\title{
Study of the Knowledge, Attitudes and Behavioral Practices of Bangui University Students in the Field of HIV / AIDS, Central African Republic
}

\author{
Kobangué $\mathrm{L}^{1 *}$, Tékpa $\mathrm{G}^{2}$, Kétté $\mathrm{C}^{3}$, Lénguébanga-Gabouga F1, Koffi \\ $\mathrm{D}^{1}$ and Grésenguet $\mathrm{G}^{4}$ \\ ${ }^{1}$ Department of Dermatology-Venereology of the CNHU of Bangui, Central Africa \\ ${ }^{2}$ Infectious Disease Service of Bangui Friendship Hospital, Central Africa \\ ${ }^{3}$ Psychiatry and mental health service, Central Africa
}

Research Article

Volume 3 Issue 2

Received Date: May 10, 2018

Published Date: May 21, 2018

DOI: $10.23880 /$ cdoaj-16000149

${ }^{4}$ Public Health Department of the Faculty of Health Sciences, Bangui University, Central Africa

*Corresponding author: Dr. Léon Kobangué, Department of Dermatology and Venerology of the CNHU of Bangui, Central Africa, Tel: 0023675505888; Email: kobangleon@yahoo.fr

\section{Abstract}

Introduction: HIV infection mostly affects young people between the ages of 15 and 25 . The purpose of this study was to study the knowledge of infection among students and their behavior towards the pandemic.

Materials and methods: This was a cross-sectional study from October to December 2015 among students in the first four years of medicine and law at the University. The variables studied were socio-demographic and behavioral.

Results: Of a total of 427 respondents, 366 (85.7\%) agreed to answer our questionnaire; 75.1\% of whom were boys. The average age of the respondents was 27 years old. Singles (81.1\%) were followed by common-law unions (17.2). Students lived with parents (49.5\%) and university housing (23.5\%).0f 366 respondents, 11\% had recognized a history of STIs. About $94.2 \%$ of the respondents cited at least the 4 modes of HIV transmission and $82 \%$ the 3 prevention methods with abstinence priority (37.2\%). About $99.5 \%$ of subjects had heard about screening. More than $85.8 \%$ of the respondents had already done the screening at least once. About $29.8 \%$ of the respondents were for abstinence, $20.2 \%$ for fidelity and $11.7 \%$ for condom use. About $96.7 \%$ of respondents said they changed risk behaviors after knowing about HIV. Out of 356 students, $97.3 \%$ had unprotected sex at least once. The number of partners met was 0 to 5 (42.1\%), 6 and more than 20 partners (4.1\%). The weekly frequency of intercourse was greater than $2(22 \%)$ and $62.3 \%$ had a number of current sexual partners $\leq 2$. The mode of penetration was sex-sex (75\%), sex-anus (18\%) and $63.9 \%$ of students still used condoms.

Keywords: HIV; Students ; University ; Bangui ; Central African Republic 


\section{Introduction}

AIDS is among the leading causes of death in the world and remains the first in Africa through opportunistic infections. The fight against this scourge involves education, voluntary testing and treatment [1]. Acceptability and accessibility are the two most important aspects for the success of any HIV testing program [2]. The Central African Republic is hard hit by this pandemic. The national HIV prevalence among adults aged 15-49 is $4.9 \%$ in 2010 compared to $6.2 \%$ in 2006 . The prevalence is higher among the most educated. It is $9.3 \%$ for women and $3.9 \%$ for men with secondary or higher education, compared to $4.0 \%$ and $3.8 \%$, respectively, for the noneducated $[3,4]$. In addition, a cross-sectional survey of a sample of 422 students from Bangui University in 1999 showed that students had an average age of 24.9 years for girls and 26.1 years for boys. Sixty-nine point four percent (69.4\%) had their first sexual intercourse between the ages of 15 and 19 . These students had at least two partners in $62.1 \%$ of cases and $58.3 \%$ of parents had at least one parent. To avoid pregnancy, boys preferred condoms, while girls mostly used the Ogino method. Fear of HIV transmission was expressed by $27.4 \%$ of female students [5]. The objectives of this study, which aims to describe the sociodemographic profile of the students of the Faculty of Law and Legal Sciences (FDSJ) and the Faculty of Health Sciences (FACSS), to appreciate their global knowledge of HIV and their behavior change.

\section{Material and Methods}

This was a prospective cross-sectional descriptive study from October to December 2015, ie three (3) months of study. The population consisted of all students in the first four years of law and medicine. The sample size depended on the number of consenting students. Students were informed of the study by a campaign that involved academic authorities. Included were the consenting students. Excluded were those from other institutions and other levels of education and reluctant. A questionnaire corrected after a pre-survey was administered. The data were collected from a selfadministered questionnaire of 30 questions with a consent form, completed anonymously and containing socio-demographic data (age, sex, faculty, department, level of study, marital status; place of residence), sexual risk and prevention behaviors (age of first sexual intercourse, number of sexual partners to date, number of current sexual partners, motivation of first sexual intercourse, sexual penetration patterns, attendance prostitutes, sex during the menses, prevention methods against STIs and HIV / AIDS, condom use), knowledge about HIV / AIDS and testing (knowledge of a person with HIV, HIV transmission, hearing about screening, the importance of screening, the behavior to be adopted to avoid catching STIs or HIV; behavior change after knowledge of HIV / AIDS). This questionnaire was submitted and collected by hand from each student. Some accepted to fill it on the spot, others preferred to fill it deferred within 24 to 48 hours. The data capture and analysis were carried out on Epi Info software version 7 and Excel 2010. Our research protocol has been validated by the Scientific Committee acting as the Ethics Committee.

\section{Results}

Of a total of 427 respondents, 366 gave their consent and agreed to answer our questionnaire; a participation rate of $85.71 \%$. The refusal rate was $14.29 \%$. The average age of the respondents was 27 years ( \pm 3 years). The median age was 28 years with extremes of 19 and 40 years. Of a total of 366 respondents, 275 were boys or 75.1\%; which gives an equal sex ratio 3.02. FDSPJ was more represented with 290 respondents, ie $79.2 \%$. Students in the 3rd year were the most represented with 198 , or $54.1 \%$, followed by students in the 4 th year with 133 or $36.3 \%$. On the marital side, singles were more represented $(81.1 \%)$, followed by common-law unions (17.2\%), divorced (1.6\%) and married (1.1\%). Students lived with parents $(49.5 \%)$, university housing $(23.5 \%)$, home $(21.3 \%)$ and guardians (5.7\%). Of the 366 students, $97.3 \%$ admitted to having had unprotected sex intercourse at least once. The number of partners encountered in the respondents' lives ranged from 0 to 5 (42.1\%), from 6 to $10(42.1 \%)$, from 11 to $15(17.5 \%)$, from 16 to $20(12.6 \%)$ and more than 20 partners (4.1\%). Motivations for sex were love (58\%), sexual desire (28\%) and curiosity (14\%). The weekly frequency of intercourse was less than or equal to $2(78 \%)$ and greater than 2 in $22 \%$. Of the 366 students, $62.3 \%$ had 1 or 2 current partners. In the series, 228 respondents (62.3\%) had a number of current sexual partners $\leq 2$. Sex-sex penetration was predominant at $75 \%$, followed by sexanus (18\%) and sex-mouth penetration (7\%). Two hundred and sixty-three (263) respondents did not attend prostitutes, ie $71.9 \%$. Eighty-two (82) subjects had sex during the menses, ie $22 \%$. Of the respondents, 234 still used condoms during sexual intercourse, or $63.9 \%$. Of a total of 366 respondents, 39 claimed to have contracted an STI, or $11 \%$. In terms of knowledge, 329) subjects $(90 \%)$ reported knowing personally someone with HIV. Figure 1 shows the distribution of respondents according 
to their level of knowledge of the mode of transmission of HIV; 345 respondents $(94.2 \%)$ cited at least the 4 modes of transmission of HIV. The top 3 most popular modes were syringe use, sex intercourse and blood transfusion. About $5.8 \%$ of students reported mosquito transmission, shared meals and shared toilets

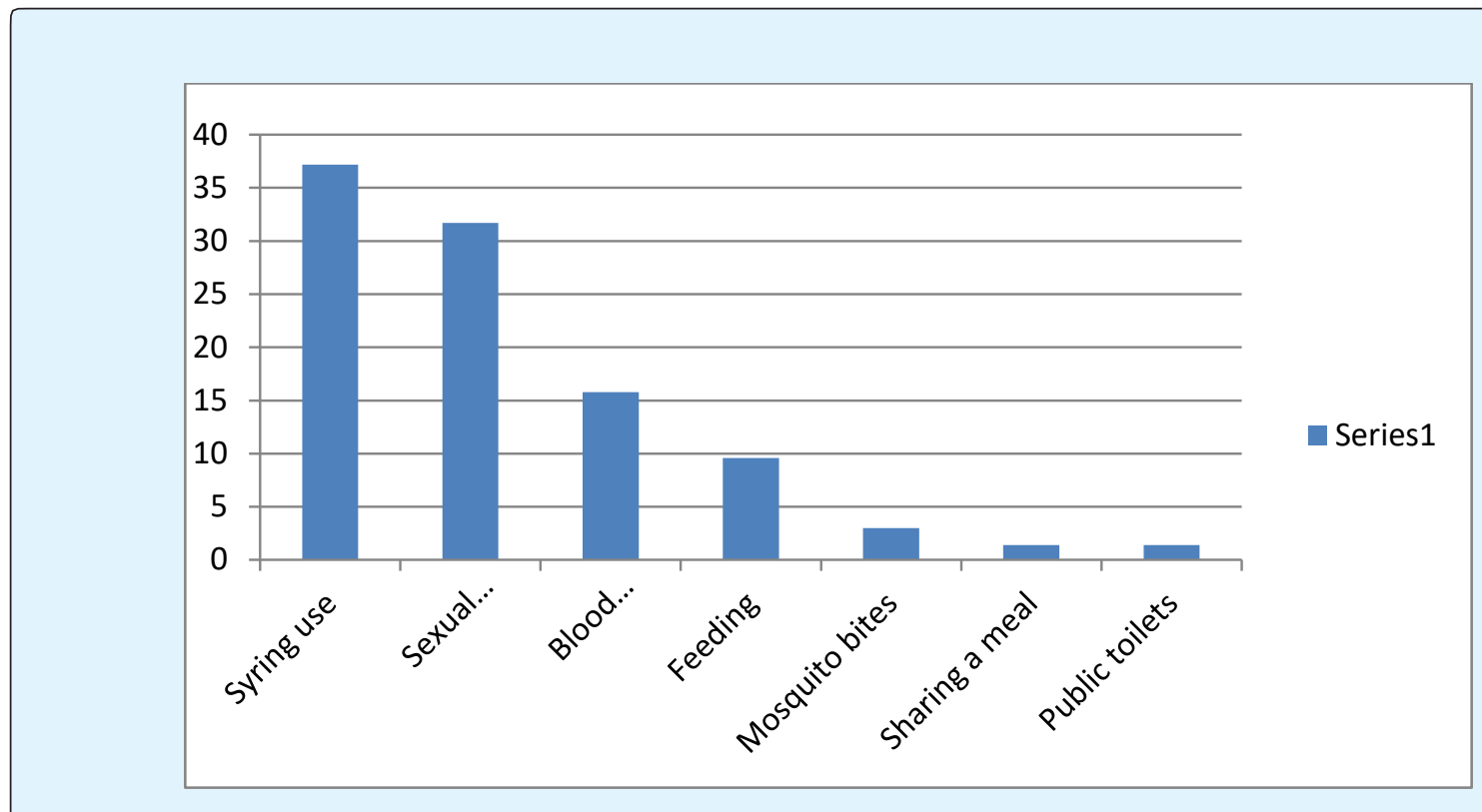

Figure 1: Distribution of respondents according to their level of knowledge of the mode of HIV transmission.

The distribution of respondents according to their level of knowledge of the HIV prevention mode Figure 2 showed that 300 out of 366 students (82\%) cited at least the three (3) prevention methods, with abstinence priority, fidelity and wearing condoms. Twenty-eight (28) respondents had a feeling of vulnerability, $7.7 \%$ versus $39.6 \%$ of no and $52.7 \%$ of no response. Three hundred and sixty-four (364) subjects had heard about screening, a rate of $99.5 \%$. Of the students, $314(85.8 \%)$ had been tested at least once, and $361(98.6 \%)$ had at least two benefits of screening. Table 1 summarizes the distribution of respondents by behavior modification to avoid HIV; $50.5 \%$ of the 366 respondents did not know if they could avoid HIV by modifying behavior. Figure 3 reveals the students' knowledge of the behaviors to avoid STI and HIV infections: the majority was for abstinence and fidelity. Three hundred and fifty-four (354) or $96.7 \%$ of the respondents stated that they had changed their risk behaviors after knowing about HIV

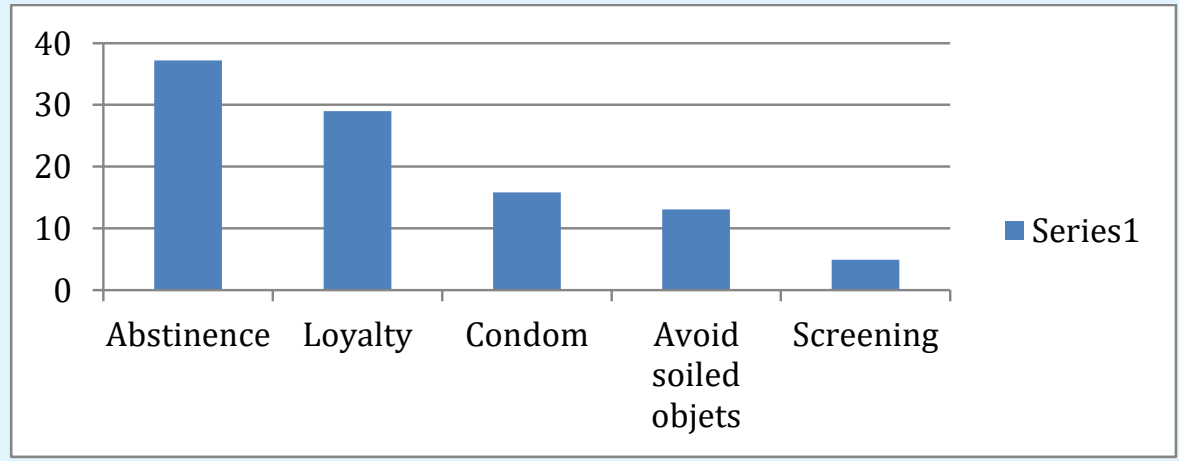

Figure 2: Distribution of respondents according to their level of knowledge of the mode of HIV prevention. 


\begin{tabular}{|c|c|c|}
\hline Can we avoid HIV by modifying the behavior? & Numbers & Percentage \\
\hline No answer & 185 & 50,5 \\
\hline Yes & 175 & 47,8 \\
\hline No & 6 & 1,6 \\
\hline Total & $\mathbf{3 6 6}$ & $\mathbf{1 0 0 , 0}$ \\
\hline
\end{tabular}

Table 1: Distribution of respondents by their behavior modifications to avoid HIV.

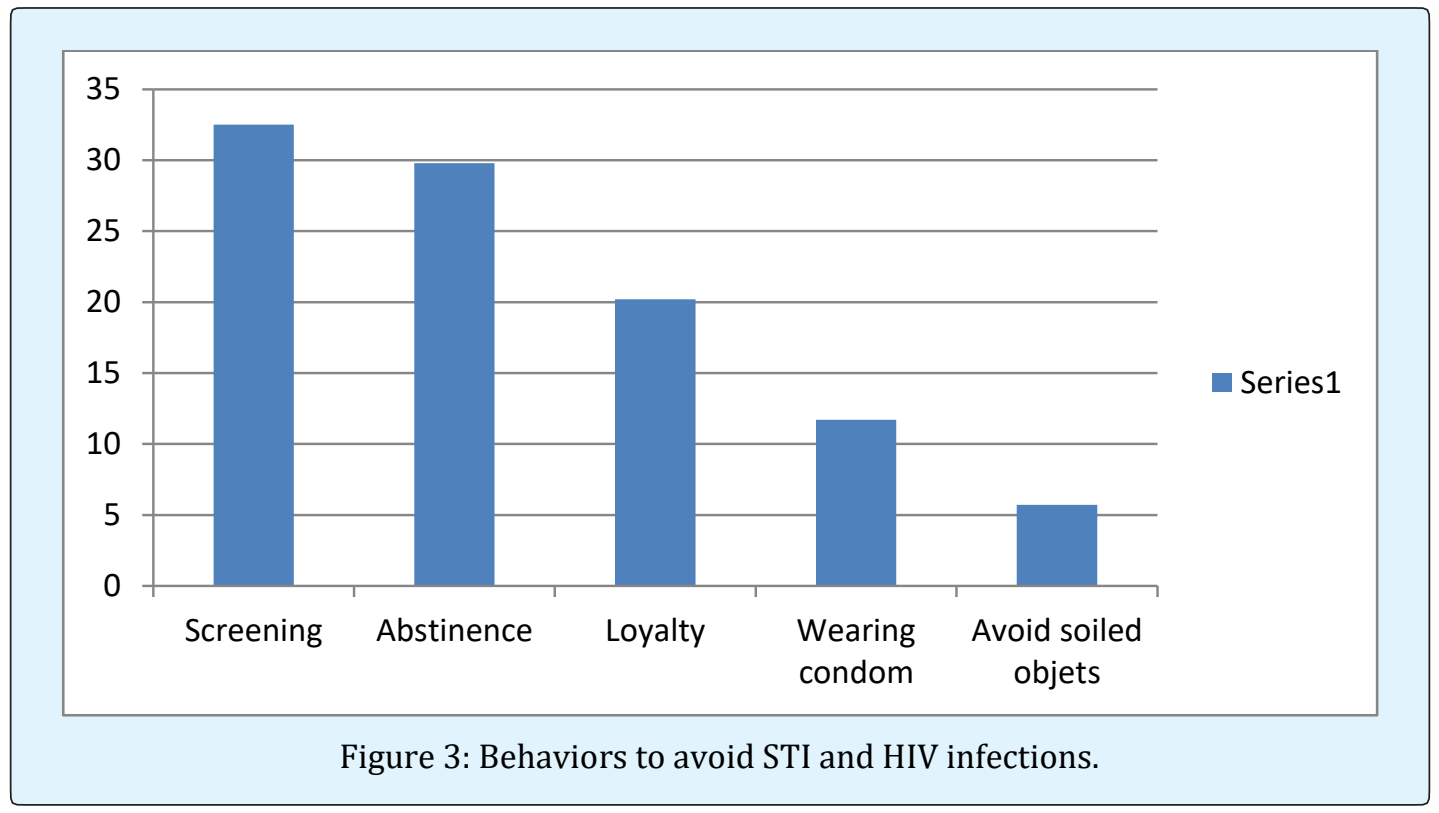

\section{Discussion}

The study took place at the University of Bangui in the faculties of health sciences and law, political and legal sciences specifically among students in 3rd, 4th and 5th having given their informed consent. During this study, 427 questionnaires were distributed, of which 366 students agreed to answer. Many of the answers provided were therefore purely declarative and difficult to verify. Different biases were likely present in the protocol of this study. It must be emphasized that this survey collected the opinions of the students and not their actual daily practices. The presence of multiple-choice answers, despite the possibility of adding a free answer, could lead to a more important choice than in the case of a completely free answer. Socio-political instability and the difference in timing between the two study sites did not allow data to be collected over a longer period. On a sociodemographic level, the average age of the respondents was 27 years, corroborating data reported in the Central African Republic and Côte d'Ivoire where the average age was 26 years and 26.1 years respectively [5,6]. On the other hand, our results revealed older respondents than those identified by Garenou, et al. [7] and Emilie Bruneel
[8]; this could be explained by strikes sometimes prolonged at the University of Bangui (UB) and the sociopolitical crisis that our country is going through prolonging the students' schooling. Moreover, the presence of student civil servants can be evoked. The respondents in the 3rd year were the most represented (54.1\%), followed by those in the 4 th year $(36.3 \%)$. This result corroborates that of Akoto [9]. The higher one goes up to the higher class, the more the number decreases. Most of the respondents were single (80.1\%). This result is almost similar to those of Tiembré and Toudeft $[6,10]$. Bruneel [8] and Sépou [5] found a rate slightly lower than that of our study (52\% and 55.2\%). In terms of knowledge of HIV infection, $82 \%$ of the surveyed students were aware of ways to prevent HIV / AIDS. This result is super imposable to those of some African authors [11,12]. The AIDS and Listening Outreach Unit has done a lot of work in local outreach campaigns on prevention in the student environment and makes condom accessible on campus. The school and university health center through its daily sensitization facilitated a better knowledge of the students on the means of prevention. In our study, $90 \%$ of the students surveyed said they knew someone with HIV. This result is similar to that of Toudeft [10] (90\%). 
Bruneel had found a lower rate than our study (4\%). This may be related to a high prevalence of HIV in our country. However, there is a statistically significant link between getting tested and knowing someone with HIV. In the survey, $94.2 \%$ of students knew at least the 4 modes of transmission of HIV / AIDS using dirty syringes (37.2\%), followed by unprotected sex, blood transfusion and breast feeding. These results corroborate those of Bruneel and Sawadogo (90\% and 98.6\%). However, Etsé [13] in Benin and Toudeft [10] in Algeria found lower rates $(60.8 \%$ and $60 \%$ ); this would always be explained by the scale of the campaign at the University of Bangui. More thanhalf of the respondents $(52.7 \%)$ were unaware of the possibility of getting HIV or not. In addition, $7.7 \%$ of students do not exclude the possibility of one day being reached by HIV / AIDS, while for $39.6 \%$, the possibility of being reached by HIV does not scratch the surface of their spirit. Akoto [9] had found a higher rate than our study $(61.17 \%$ vs. $28.33 \%$ ). These results would reflect the inefficiency of awareness in this area at BU. In the study, $85.7 \%$ of students surveyed said they had been tested for HIV. This result is slightly higher than that of Sawadogo (67.6\%). Some authors found lower rates $(32 \%, 29.5 \%$ and $17 \%)$ $[6,8,10]$. This is linked to the awareness-raising work carried out by the UB AIDS Info Antenna at the different faculties. The Catholic University Center (CCU) has had to organize many voluntary testing campaigns at UB in partnership with the National Association of Central African Students and the WHO. Most screening tests are done at the request of the student, on a voluntary basis during mass campaigns. With knowledge about AIDS, $96.7 \%$ of the students surveyed claimed to have changed their behavior with priority for screening, followed by abstinence, fidelity and wearing a condom. This result is higher than that of Tiembré (56.7\%); this would always be related to the degree of $\mathrm{BU}$ awareness. In terms of behavioral change, $97.3 \%$ of respondents reported having had sex intercourse. These results revealed more active students than those identified by Bruneel and Karfo, et al. $[8,11]$. In the series, $62.3 \%$ of students reported having had at least 2 current sexual partners. This result is almost similar to that of Sépou (62.1\%) and Bruneel (64\%). Tiembré, Karfo, Sawadogo and found a rate slightly lower than that of our study $(27.27 \%, 32.4 \%$ and $31.5 \%)[6,11,12]$. However, there is no statistically significant difference between the number of current sexual partners and the screening test (Chi2: 0.546, $\mathrm{p}=$ 0.460 ). In our survey, $18 \%$ of students had genito-anal relationships. This result is higher than that of Etsé et al (9\%) [13]. Seven percent of respondents had genito-oral relationships. Slightly in Côte d'Ivoire found a higher rate, $36.7 \%$ that would probably be related to morals [6]. In our study, $28.1 \%$ of respondents had sex with prostitutes. This result corroborates that of Toudeft (24\%). It is higher than those of other African authors $(11.8 \%$ and 17.26\%) [6,11]. Precariousness and socio-political troubles favor prostitution in our country. However there is no statistically significant link between HIV testing and attendance of prostitutes (Chi2 $=3.518, p=0.061$ ). In our series, $22 \%$ of students had sex during menstruation; which is likely to expose them to contamination if the reports are unprotected. We did not find any data in the literature. However, there is no statistically significant difference between HIV testing and sexual intercourse during menstruation. The systematic use of condoms varies according to the studies [11]. In fact, $63.9 \%$ of students still used condoms during sex and $36.1 \%$ used them irregularly. These results corroborate those of Karfo and Toudeft $[9,11]$. On the other hand, it is lower than that of Sawadogo in Burkina Faso (79.50\%) [12] and lower than that of Tiembré in Côte d'Ivoire (14.5\%). This variation would it be due to a difference between the methodological approaches. Our series showed that $11 \%$ of respondents stated that they had been reached once with an STI. This result is almost similar to that of Akoto (10\%). Karfo had found a lower rate $(2.3 \%)$ than that of our study. On the other hand Tiembré found a result higher than that of our study (35.2\%). The majority of our respondents stated that they never have an STI; this result is to be taken with reserve. Indeed, Ariane Metiegan in Kenya had noted the presence of STIs in her series among medical students in pharmacy and odontostomatology school [14].

\section{Conclusion}

It emerges from this study that more than $90 \%$ of students have had a first sexual encounter at 16 years old. More than a third of students recognize more than two sexual partners in the past year (multi partnership). The means of transmitting HIV-AIDS seem well known to students as found in other studies. Nearly one-third of students attend prostitutes. A quarter of the respondents use the modes of ano-oral penetration. More than a third of the students surveyed do not always use condoms during sex. The vast majority of students changed their behavior with emphasis on abstinence, fidelity and testing. Most students have been screened at least once. Motivation: love, Weekly frequency of sexual intercourse> 2, Knowledge of a person with HIV, Knowledge of the importance of screening. Progress in changing risky sexual behavior and accessibility of testing remains to be made in favor of UB students. 


\section{Clinical Dermatology Open Access Journal}

\section{References}

1. Onusida (2007) Rapport sur l'épidémie du SIDA, pp: 25.

2. Mutula F (2003) The acceptability and accessibility of voluntary HIV / AIDS testing among pregnant women in the 3 urban health zones of Bukavu and in the rural health zone of Katana. Mémoire, pp: 60.

3. (2006) Ministère du Plan, de l'Economie et de la Coopération Internationale. Rapport de synthèse des résultats du troisième recensement général de la population et de l'habitat de 2006. Bangui, juin, pp: 123.

4. (2010) Ministère du Plan, de l'Economie et de la Coopération Internationale.Enquête par Grappe à Indicateurs Multiples- MICS IV couplée avec la sérologie VIH. RCA 2010, Rapport final, Bangui, pp: 196.

5. Sepou A, Nguembi E, Yanza MC, Ngbale R, Nali MN (2004) Comportement sexuel des étudiants de l'université de Bangui (Centrafrique). Med Trop 64: 163-167.

6. Tiembre I, Konan YE, Attoh-Toure H, Dagnan S, Benie J, et al. (2007) Infections sexuellement transmissibles et utilisation du préservatif masculin en milieu estudiantin : à propos d'une enquête réalisée dans une résidence universitaire d'Abidjan (Côte d'Ivoire). MédAfr Noire 54(4): 193-198.

7. Garenne M, Madison M, Tarantola D (1995) Conséquences déinographiques du sida à Abidjan. Paris, CEPED, 10: 198.

8. Bruneel E (2015) Assessment of the knowledge of young people aged 18 to 25 about HIV infection and the impact on their screening: an observational study of 683 students from the Hauts-de-Seine. Thèse de doctorat en Médecine humaine et pathologie. Paris, pp: 72.

9. Akoto AEC (2010) Sexuality and HIV / AIDS in academia: the case of Muslim students of the INB BAZ mosque of the University of Cocody-Abidjan. Memoire pp: 40 .

10. Toudeft F (2010) Etude sur les connaissances, attitudes et comportements des jeunes universitaires en matière de l'infection à VIH/SIDA. Evaluation des actions de proximité à l'université des Sciences et Technologie Houari Boum ediene de Bab Ezzouar d'Alger (USTHB). Enquête comportementale, Alger, pp: 42.

11. karfo K, Tiendrebeogo C, Ouango JG, Ouedraogo A (2010) Comportements sexuels à risque d'infection par le VIH chez les étudiants de l'université de Ouagadougou au Burkina Faso. Revue française de psychiatrie et de psychologie médicale 14(112): 2226.

12. Sawadogo A, Some FB, Lokpo K (2010) Perceptions, attitudes et pratiques des universités burkinabé face aux personnes vivant avec le VIH/SIDA. Revue Africaine de Développement de l'éducation. ROCARE, pp: 203-224.

13. Etse DS, Mesnerem GB, Kpante B, Kossi D, Ameyo S, et al. (1999) Sexual Behavior, Knowledge and Attitudes of University of Benin (Togo) Students Facing AIDS and Sexually Transmitted Diseases. Cahiers d'études et de recherches francophones / Santé 9(2): 101-109.

14. Tatientsé AMT (2009) Connaissances, attitudes et pratiques comportementales liées aux IST et au VIH/SIDA des étudiants de la FMPOS. Thèse Doct Med, Kénia 1- 85. 